\title{
Upper esophageal sphincter pressure in patients with Chagas' disease and primary achalasia
}

\section{R.O. Dantas}

Departamento de Clínica M édica, Faculdade de Medicina de Ribeirão Preto, Universidade de São Paulo, Ribeirão Preto, SP, Brasil

\section{Correspondence \\ R.O. Dantas \\ Departamento de Clínica Médica \\ Faculdade de Medicina de \\ Ribeirão Preto, USP \\ 14049-900 Ribeirão Preto, SP \\ Brasil \\ Fax: + 55-16-633-6695}

Research supported by FINEP and Pronex (No. 42/97). Publication supported by FAPESP.

Received October 21, 1999 Accepted February 8, 2000

\section{Abstract}

The most important component of the upper esophageal sphincter (UES) is the cricopharyngeal muscle. During the measurement of sphincter pressure the catheter passed through the sphincter affects the pressure value. In Chagas' disease and primary achalasia there is an esophageal myenteric plexus denervation which may affect UES pressure. We measured the UES pressure of 115 patients with Chagas' disease, 28 patients with primary achalasia and 40 healthy volunteers. We used a round manometric catheter with continuous perfusion and the rapid pull-through method, performed in triplicate during apnea. Pressures were measured in four directions, and the direction with the highest pressure (anterior/posterior) and the average of the four directions were measured. The highest UES pressure in Chagas' disease patients without abnormalities upon radiologic esophageal examination $(\mathrm{N}=63)$ was higher than in normal volunteers $(142.8 \pm 47.4$ $\mathrm{mmHg}$ vs $113.0 \pm 46.0 \mathrm{mmHg}$, mean $\pm \mathrm{SD}, \mathrm{P}<0.05)$. There was no difference in UES pressure between patients with primary achalasia and patients with Chagas' disease and similar esophageal involvement and normal volunteers $(\mathrm{P}>0.05)$. There was no difference between patients with or without esophageal dilation. In the group of subjects less than 50 years of age the UES pressure of primary achalasia $(\mathrm{N}=$ 21) was lower than that of Chagas' disease patients with normal radiologic esophageal examination $(\mathrm{N}=41)$, measured at the site with the highest pressure $(109.3 \pm 31.5 \mathrm{mmHg}$ vs $149.6 \pm 45.3 \mathrm{mmHg}$, $\mathrm{P}<0.01)$ and as the average of the four directions $(64.2 \pm 17.1 \mathrm{mmHg}$ vs $83.5 \pm 28.6 \mathrm{mmHg}, \mathrm{P}<0.05)$. We conclude that there is no difference in UES pressure between patients with Chagas' disease, primary achalasia and normal volunteers, except for patients with minor involvement by Chagas' disease, for whom the UES pressure at the site with the highest pressure was higher than the pressure of normal volunteers and patients with primary achalasia.

\section{Introduction}

The most important component of the upper esophageal sphincter (UES) is the cricopharyngeal muscle (1-3) with the adjacent portions of the cervical esophagus

\section{Key words}

- Upper esophageal sphincter

- Megaesophagus

- Achalasia

- Chagas' disease muscle and the inferior pharyngeal constrictor muscle contributing to the sphincter function. This high pressure zone at the pharyngeal-esophageal transition presents changes in pressure with stress (4), sleep (5), pharyngeal stimulation with water (6), intraesoph- 
ageal balloon distention $(7,8)$, intraesophageal air infusion (9), anesthesia (10), respiration (5), and the movement of a catheter inside the sphincter $(7,10)$.

UES pressure is controlled by the central nervous system through the vagus nerve $(6,11)$ in response to sensory input from the oropharynx and esophagus and also directly by the central nervous system (11).

Primary achalasia, of unknown etiology $(12,13)$, and Chagas' disease, caused by the flagellate protozoan Trypanosoma cruzi $(14,15)$, cause a loss of esophageal myenteric plexus $(13,14)$ with similar clinical, radiological and manometric manifestations, although some differences between the two conditions may be seen (16). It is suggested that esophageal sensitivity decreases in these diseases $(17,18)$, a fact that may change the UES response to different stimuli.

As the presence and movement of a manometric catheter in the UES reflexively increases sphincter pressure, our hypothesis is that in diseases with impairment of esophageal innervation the pressure response to the catheter movement is not the same as in normal subjects. Also, it is possible that the UES pressure of patients with esophageal dilation differs from that of patients who do not have esophageal dilation. The aim of this investigation was to compare the UES pressure measured by the rapid pull-through tech-

Table 1 - Characteristics of the population studied.

\begin{tabular}{|c|c|c|c|c|c|c|}
\hline & \multirow[t]{2}{*}{ Number } & \multicolumn{2}{|c|}{ Gender } & \multirow{2}{*}{$\begin{array}{c}\text { Age } \\
(\text { mean } \pm S D)\end{array}$} & \multicolumn{2}{|c|}{ Dysphagia } \\
\hline & & $M$ & $\mathrm{~F}$ & & Yes & No \\
\hline Normal volunteers & 40 & 20 & 20 & $37.5 \pm 14.3$ & 0 & 40 \\
\hline \multicolumn{7}{|l|}{ Chagas' disease } \\
\hline Normal radiology & 63 & 47 & 16 & $43.3 \pm 12.7$ & 15 & 48 \\
\hline Abnormal radiology & 52 & 30 & 22 & $51.3 \pm 10.8$ & 41 & 11 \\
\hline No dilation & 42 & 24 & 18 & $51.5 \pm 10.8$ & 31 & 11 \\
\hline Dilation & 10 & 6 & 4 & $50.7 \pm 11.3$ & 10 & 0 \\
\hline \multicolumn{7}{|l|}{ Primary achalasia } \\
\hline Abnormal radiology & 28 & 8 & 20 & $39.5 \pm 14.4$ & 28 & 0 \\
\hline No dilation & 14 & 4 & 10 & $44.5 \pm 14.0$ & 14 & 0 \\
\hline Dilation & 14 & 4 & 10 & $34.4 \pm 13.5$ & 14 & 0 \\
\hline
\end{tabular}

nique in normal volunteers, patients with Chagas' disease and patients with primary achalasia.

\section{Material and Methods}

We studied 115 patients with a positive serological test for Chagas' disease, 28 patients with a clinical, radiological and manometric diagnosis of primary achalasia (12), and 40 healthy volunteers. The patients with primary achalasia had a negative serological test for Trypanosoma cruzi, no heart or colon diseases and did not live in places where Chagas' disease was endemic.

The results of radiological esophageal examination in Chagas' disease patients showed normal transit in 63 and abnormal transit in 52 patients. Of the latter patients, 10 had dilation and 42 did not (Table 1). All patients with primary achalasia $(\mathrm{N}=28)$ showed esophageal retention of barium sulfate in the esophagus during radiological examination, with dilation in 14 and no dilation in 14. Normal volunteers ranged in age from 21 to 70 years, Chagas' disease patients from 19 to 70 years and patients with achalasia from 19 to 69 years. Dysphagia was a complaint in all patients with achalasia, in $49 \%$ of patients with Chagas' disease, and was absent in all volunteers (Table 1). Informed written consent was obtained from each volunteer and patient. The study was approved by the Human Research Committee of the Hospital das Clínicas of Ribeirão Preto.

For measurement of UES pressure we used a manometric method previously described $(19,20)$ with a round eight-lumen polyvinyl catheter measuring $4.5 \mathrm{~mm}$ in external diameter and $0.8 \mathrm{~mm}$ in internal diameter (Arndorfer Specialties Inc., Greendale, WI, USA). The four distal openings were at the same level, at $90^{\circ}$ angles, and were used to measure UES pressure. The four proximal openings were spaced $5 \mathrm{~cm}$ apart, also at $90^{\circ}$ angles. The lumens of the catheter were 
connected to an external pressure transducer (Model RP 1500, Narco Bio Systems, Narco Scientific, Houston, TX, USA) connected in turn to a four-channel physiograph (Model MK IV, Narco Bio Systems). The lumens were perfused with distilled water at a rate of $0.5 \mathrm{ml} / \mathrm{min}$ by low-compliance continuous perfusion.

All volunteers and patients were studied in the supine position. The catheter was inserted through the nose into the stomach after an overnight fast. After the manometric examination of the lower esophageal sphincter and esophageal body $(19,20)$ the UES pressure was recorded using the four distal openings and the rapid pull-through technique. The subjects were instructed to stop breathing during the movement of the catheter, which was pulled by hand at the velocity of $1 \mathrm{~cm} / \mathrm{s}$ by a trained technician. UES pressures were recorded in triplicate, with the intraesophageal pressure used as reference. The results were the mean of the three pressures measured at the site where they were highest, and the mean of the twelve values recorded.

The results are reported as mean $\pm \mathrm{SD}$. Analysis of variance and the Tukey-Kramer test for multiple comparisons were used for data analysis. Differences were considered to be significant when $\mathrm{P}<0.05$.

\section{Results}

There was a considerable overlap of UES pressures between patients and volunteers (Figure 1).

The highest UES pressure in Chagas' disease patients without abnormalities upon radiologic esophageal examination was higher than in normal volunteers $(\mathrm{P}<0.05$, Table 2). There was no difference between the UES pressure of patients with primary achalasia and normal volunteers, or between patients with primary achalasia and patients with Chagas' disease $(\mathrm{P}>0.05)$. There was no difference between groups when UES pressure was calculated as the average of the four directions, or when patients with or without esophageal dilation were compared $(\mathrm{P}>0.05)$.

UES pressure tended to be higher in normal volunteers and in Chagas' disease patients with normal radiologic examination aged 19-49 years than in subjects aged 50-70 years but the difference did not achieve sta-
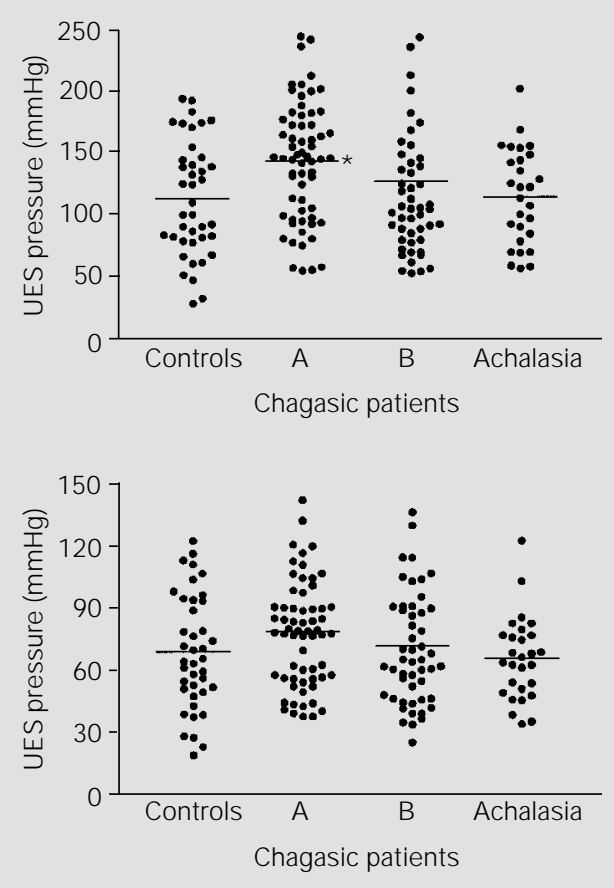

Figure 1 - Upper esophageal sphincter (UES) pressure of healthy volunteers (controls), patients with Chagas' disease and normal esophageal transit by radiologic esophageal examination (A) or abnormal esophageal transit (B), and patients with primary achalasia, measured at the site with the highest pressure (top) or at the four sites of the sphincter (bottom). $* \mathrm{P}<0.05$ vs controls.

Table 2 - Upper esophageal sphincter pressures $(\mathrm{mmHg})$ of normal volunteers, patients with Chagas' disease and patients with primary achalasia, measured at the site with the highest pressure and as the average of the four sites where the pressures were measured.

Data are reported as mean $\pm \mathrm{SD} ; * \mathrm{P}<0.05$ compared to volunteers (Tukey-Kramer test).

\begin{tabular}{lccc}
\hline & Number & Highest & Average \\
\hline $\begin{array}{l}\text { Normal volunteers } \\
\text { Chagas' disease }\end{array}$ & 40 & $113.0 \pm 46.0$ & $68.8 \pm 27.6$ \\
$\quad$ Normal radiology & 63 & $142.8 \pm 47.4^{*}$ & $78.8 \pm 27.3$ \\
Abnormal radiology & 52 & $126.9 \pm 62.1$ & $71.7 \pm 29.1$ \\
$\quad$ No dilation & 42 & $130.7 \pm 61.7$ & $72.8 \pm 30.3$ \\
$\quad$ Dilation & 10 & $100.7 \pm 38.3$ & $66.9 \pm 24.0$ \\
$\begin{array}{l}\text { Primary achalasia } \\
\text { Abnormal radiology }\end{array}$ & 28 & $114.1 \pm 38.3$ & $65.5 \pm 20.0$ \\
$\quad$ No dilation & 14 & $114.0 \pm 44.6$ & $64.2 \pm 23.5$ \\
Dilation & 14 & $114.3 \pm 32.6$ & $66.8 \pm 16.6$ \\
& & &
\end{tabular}


tistical significance $(P>0.05$, Table 3$)$. In the group of subjects aged 19-49 years the UES pressure measured at the site with the highest pressure was higher in patients with Chagas' disease and normal radiologic examination than in normal volunteers or patients with primary achalasia $(\mathrm{P}<0.05$, Table $3)$. The average pressure of patients with primary achalasia was also lower than that of patients with Chagas' disease and normal radiologic esophageal examination $(\mathrm{P}<0.05$, Table 3). There were no differences in the group of subjects aged 50-70 years. Patients with Chagas' disease without dysphagia ( $\mathrm{N}$ $=59$ ) had higher UES pressure (highest: $149.3 \pm 57.2 \mathrm{mmHg}$, average: $81.7 \pm 30.4$ $\mathrm{mmHg}$ ) than patients with Chagas' disease and dysphagia $(\mathrm{N}=56$, highest: $121.0 \pm 50.3$ $\mathrm{mmHg}$, average: $69.3 \pm 25.1 \mathrm{mmHg}$ ) and patients with primary achalasia $(\mathrm{N}=28)$, all with dysphagia (highest: $114.1 \pm 38.3$, average: $65.5 \pm 20.0 \mathrm{mmHg})(\mathrm{P}<0.01)$.

\section{Discussion}

There were no differences in UES pressure between patients with similar esophageal involvement by Chagas' disease and achalasia. These pressures also did not differ from those of normal volunteers. The patients with Chagas' disease and no radiologi- cal esophageal abnormalities showed higher pressure than normal volunteers at the site with the highest UES pressure. In the 19-49 year group UES pressure was also higher than in patients with achalasia.

The UES is a tonically contracted segment with the resting pressure within the sphincter exibiting marked radial asymmetry $(7,21,22)$. The highest UES pressures are in the anteroposterior direction of the cricopharyngeal muscle $(7,21,22)$. With the catheter movement the muscle increases its tonus $(7,10)$. The resting pressure shows considerable variation with environmental stimuli. The continuous rapid pull-through technique itself or water perfusion into the UES zone may stimulate the UES to contract (7). The cricopharyngeal response to the stimulus may be different in patients with Chagas' disease and minor esophageal involvement.

The cricopharyngeus muscle receives its motor nerve supply from the pharyngeal branch of the vagus (23). The afferent sensory pathways from the pharynx and larynx that control swallowing travel via the glossopharyngeal, trigeminus, and vagus nerves to the nucleus tractus solitarius. Spinal afferents from the proximal esophagus, although sparse, arise from cervical and dorsal root ganglia (11). Some sensory structures are

Table 3 - Effect of age on upper esophageal sphincter pressures $(\mathrm{mmHg})$ of two groups of normal volunteers, patients with Chagas' disease and patients with primary achalasia, measured at the site with the highest pressure and as the average of the four sites where the pressures were measured.

Data are reported as mean $\pm \mathrm{SD}$. $* \mathrm{P}<0.05$ vs volunteers; $* * \mathrm{P}<0.01$ vs Chagas with normal radiology; $+\mathrm{P}<0.05$ vs Chagas with normal radiology (Tukey-Kramer test).

\begin{tabular}{|c|c|c|c|c|c|c|c|c|}
\hline & \multicolumn{4}{|c|}{$19-49$ years } & \multicolumn{4}{|c|}{$50-70$ years } \\
\hline & Number & Age & Highest & Average & Number & Age & Highest & Average \\
\hline Normal volunteers & 28 & $29.1 \pm 6.1$ & $116.7 \pm 47.7$ & $72.7 \pm 28.1$ & 12 & $57.1 \pm 6.4$ & $104.4 \pm 42.5$ & $59.5 \pm 24.9$ \\
\hline \multicolumn{9}{|l|}{ Chagas' disease } \\
\hline Normal radiology & 41 & $36.2 \pm 9.3$ & $149.6 \pm 45.3^{*}$ & $83.5 \pm 28.6$ & 22 & $56.6 \pm 5.0$ & $130.2 \pm 49.6$ & $70.1 \pm 22.8$ \\
\hline Abnormal radiology & 21 & $40.3 \pm 5.8$ & $121.0 \pm 54.8$ & $70.0 \pm 28.2$ & 31 & $58.8 \pm 5.7$ & $130.8 \pm 67.2$ & $72.8 \pm 30.2$ \\
\hline \multicolumn{9}{|l|}{ Primary achalasia } \\
\hline Abnormal radiology & 21 & $32.9 \pm 9.5$ & $109.3 \pm 31.5^{* *}$ & $64.2 \pm 17.1^{+}$ & 7 & $59.1 \pm 5.9$ & $128.4 \pm 54.7$ & $69.5 \pm 28.4$ \\
\hline
\end{tabular}


located in the ganglia of the myenteric plexus (11).

The pressures recorded in the UES arise from two sources: contraction of the sphincter muscle and passive elastic forces generated in the tissues in and around the sphincter $(10,11)$. Because the UES is composed of striated muscle, its level of tonic contraction depends upon the activity of the somatic nerves supplying it $(3,11)$. The greater the neural input, the more intense the spike activity recorded on the electromyogram (EMG) and the greater the tone $(3,11)$.

The response of the UES to intraesophageal air infusion in patients with achalasia differs from the response in normal subjects (24). UES pressure decreases after intraesophageal air infusion in normal subjects whereas it increases in patients with achalasia, trapping the air inside the esophagus (24). In patients with megaesophagus consequent to Chagas' disease intraesophageal water infusion increases intraesophageal and UES pressure (25). During swallowing, increased residual pressure in the UES and reduction in the duration of UES relaxation occur in patients with achalasia $(26,27)$. Our personal observations suggest that the same abnormalities are present in patients with megaesophagus caused by Chagas' disease, but we do not have enough reliable data to reach any conclusion. Some patients with achalasia may have a serious problem with UES relaxation $(28,29)$.

The most striking abnormal microscopic finding in the esophageal body of cases of primary achalasia and Chagas' disease is a significantly lower number or total absence of myenteric ganglion cells in the proximal and distal esophagus compared with normal controls $(13,14)$. We do not know of any studies about the innervation of the UES in achalasia or Chagas' disease. Some publications have suggested that esophageal sensitivity may be partly impaired by the diseases $(17,18)$, a fact that could change the UES response to the catheter movement. We did not find differences in UES pressure in patients with esophageal dilation, who have more intense denervation (14), compared with patients without dilation and normal volunteers, an indication that the sensitivity controlled by the myenteric plexus should have no influence on the UES pressure of these patients. Studies that made reference to UES pressure in achalasia did not find differences in UES pressure from normal subjects $(24,26,27)$. In Chagas' disease one study described a low UES pressure measured by the rapid pull-through technique in patients with more marked esophagopathy (30).

We do not have an explanation for the higher pressure found in patients with Chagas' disease and minor esophageal involvement. One hypothesis is related to the premise under which these patients were studied. The patients with known esophageal disease already knew there was something wrong with their esophagus. Findings on manometry may therefore cause less anxiety. However, Chagas' disease patients without dysphagia and with no radiologic abnormality might have been more anxious, a situation which can increase UES pressure (4). Since UES pressure is dependent on the electrical activity of the cricopharyngeus muscle (3) we speculate that these patients may have a more marked increase in EMG activity during UES pressure measurement than volunteers. These patients show changes in esophageal motility, at times corresponding to complete aperistalsis (31) or simultaneous contractions (32), showing that they have some degree of esophageal denervation.

Although the groups of patients had different gender proportions, the group of normal volunteers showed that there is no gender effect on UES pressure (20). In agreement with previous reports showing that the aging process decreases UES pressure (33), we found a lower pressure in subjects over 50 years than in subjects under 50 years, but 
the difference did not achieve statistical significance.

We did not find differences in UES pressure between normal volunteers, patients with Chagas' disease and patients with primary achalasia, as determined by the rapid pull- through technique, except for patients with minor manifestations of esophageal involvement by Chagas' disease, when UES pressure at the site with the highest pressure was higher than the pressure of normal volunteers and patients with primary achalasia.

\section{References}

1. Kahrilas PJ , Dodds WJ , Dent J , Logemann J A \& Shaker R (1988). Upper esophageal sphincter function during deglutition. Gastroenterology, 95: 52-62.

2. Cook IJ, Dodds WJ, Dantas RO, Massey B, Kern MK, Lang IM, Brasseur JG \& Hogan WJ (1989). Opening mechanisms of the human upper esophageal sphincter. American J ournal of Physiology, 257: G748-G759.

3. Lang IM, Dantas RO, Cook IJ \& Dodds WJ (1991). Videoradiographic, manometric and electromyographic analysis of canine upper esophageal sphincter. American J ournal of Physiology, 260: G911G919.

4. Cook IJ, Dent J \& Collins SM (1987). Measurement of upper esophageal sphincter pressure: Effect of acute emotional stress. Gastroenterology, 93: 526532.

5. Kahrilas PJ , Dodds WJ , Dent J, Haeberle B, Hogan WJ \& Arndorfer RC (1987). Effect of sleep, spontaneous gastroesophageal reflux, and a meal on upper esophageal sphincter pressure in normal human volunteers. Gastroenterology, 92: 466-471.

6. Shaker R, Ren J , Xie P, Lang IM, Bardan E \& Sui Z (1997). Characterization of the pharyngo-UES contractile reflex in humans. American J ournal of Physiology, 273: G854-G858.

7. Kahrilas PJ , Dent J, Dodds WJ , Hogan WJ \& Amdorfer RC (1987). A method for continuous monitoring of upper esophageal sphincter pressure. Digestive Diseases and Sciences, 32: 121-128.

8. Andreollo NA, Thompson DG, Kendall GPN \& Earlam RJ (1988). Functional relationships between cricopharyngeal sphincter and oesophageal body in response to graded intraluminal distension. Gut, 29: 161-166.

9. Kahrilas PJ, Dodds WJ , Dent J, Wyman J B, Hogan WJ \& Arndorfer RC (1986). Upper esophageal sphincter function during belching. Gastroenterology, 91: 133140.
10. J acob P, Kahrilas PJ, Herzon G \& McLaughlin B (1990). Determinants of upper esophageal sphincter pressure in dogs. American J oumal of Physiology, 259: G245-G251.

11. Conklin J L \& Christensen J (1994). Motor functions of the pharynx and esophagus. In: J ohnson LR (Editor), Physiology of the Gastrointestinal Tract. 3rd edn. Raven Press, New York, 903-928.

12. Feldman M (1988). Esophageal achalasia syndromes. American J ournal of Medical Sciences, 295: 60-81.

13. Goldblum J R, Whyte RI, Orringer MB \& Appelman HD (1994). Achalasia - A morphologic study of 42 resected specimens. American J ournal of Surgical Pathology, 18: 327-337.

14. Köberle F (1968). Chagas' disease and Chagas' syndrome: the pathology of American trypanosomiasis. Advances in Parasitology, 6: 63-116.

15. Oliveira RB, Troncon LEA, Dantas RO \& Meneghelli UG (1998). Gastrointestinal manifestations of Chagas' disease. American J ournal of Gastroenterology, 93: 884889.

16. Dantas RO, Godoy RA, Oliveira RB, Meneghelli UG \& Troncon LEA (1990). Lower esophageal sphincter pressure in Chagas' disease. Digestive Diseases and Sciences, 35: 508-512.

17. Paterson WG (1997). Esophageal and lower esophageal sphincter response to balloon distention in patients with achalasia. Digestive Diseases and Sciences, 42: 106-112.

18. Ejima $F H$, Dantas RO, Simões MV, Marin Neto J A \& Meneghelli UG (1998). Intraesophageal balloon distension test in Chagas' disease patients with noncardiac chest pain. Digestive Diseases and Sciences, 43: 2567-2571.

19. Ferriolli E, Oliveira RB, Matsuda NM, Braga FJ HN \& Dantas RO (1998). Aging, esophageal motility, and gastroesophageal reflux. J ournal of the American Geriatrics Society, 46: 1534-1537.

20. Dantas RO, Ferriolli E \& Souza MAN
(1998). Gender effects on esophageal motility. Brazilian J ournal of Medical and Biological Research, 31: 539-544.

21. Winans CS (1972). The pharyngoesophageal closure mechanism: a manometric study. Gastroenterology, 63: 768-777.

22. Weihrauch TR, Brummer $A$, Biewener $H$ \& Ewe K (1980). Assessment of various factors influencing esophageal pressure measurement. I. Significance of methodical factors in intraluminal manometry. Klinische Wochenschrift, 58: 279-285.

23. Lund WS \& Ardran GM (1964). The motor nerve supply of the cricopharyngeal sphincter. Annals of Otology, Rhinology and Laryngology, 73: 599-617.

24. Massey BT, Hogan WJ, Dodds WJ \& Dantas RO (1992). Alteration of the upper esophageal sphincter belch reflex in patients with achalasia. Gastroenterology, 103: 1574-1579.

25. Godoy RA (1972). Estudo da esofagopatia chagásica crônica por meio do método eletromanométrico e da prova de metacolina em pacientes com e sem dilatação de esôfago. Revista Goiana de Medicina, 18: 1-73.

26. Dudnick RS, Castell JA \& Castell DO (1992). Abnomal upper esophageal sphincter function in achalasia. American J ournal of Gastroenterology, 87: 1712-1715.

27. Yoneyama $F$, Miyachi $M \&$ Nimura $Y$ (1998). Manometric findings of the upper esophageal sphincter in esophageal achalasia. World J ournal of Surgery, 22: 10431047.

28. Ali GN, Hunt DR, J orgensen J O, DeCarle DJ \& Cook IJ (1995). Esophageal achalasia and coexistent upper esophageal sphincter relaxation disorder presenting with airway obstruction. Gastroenterology, 109: 1328-1332.

29. Souza MAN \& Dantas RO (1998). Cricopharyngeal dysfunction in a patient with achalasia. J ournal of Clinical Gastroenterology, 26: 216-218.

30. Lobo CJ N \& Dantas RO (1994). Comparison of methods for recording esophageal sphincter pressures in Chagas' disease. 
Acta Gastroenterologica Latinoamericana, 24: 105-111.

31. Oliveira RB, Rezende Filho J, Dantas RO \& lazigi N (1995). The spectrum of esophageal motor disorders in Chagas' disease. American J ournal of Gastroenterology, 90: 1119-1124.
32. Dantas RO, Deghaide NHS \& Donadi EA (1999). Esophageal manometric and radiologic findings in asymptomatic subjects with Chagas' disease. Journal of Clinical Gastroenterology, 28: 245-248.

33. Weihrauch TR, Vallerius $P$, Alpers $H \&$ Ewe K (1980). Assessment of various fac- tors influencing esophageal pressure measurement. II. Significance of physiological factors in intraluminal manometry. Klinische Wochenschrift, 58: 287292. 